\title{
Nature versus nurture in social insect caste differentiation
}

\section{Tanja Schwander ${ }^{1,4}$, Nathan Lo ${ }^{2}$, Madeleine Beekman ${ }^{2}$, Benjamin P. Oldroyd ${ }^{2}$ and Laurent Keller ${ }^{3}$}

\author{
${ }^{1}$ Simon Fraser University, Biological Sciences, 8888 University Drive, Burnaby V5A 1S6, Canada \\ ${ }^{2}$ Behaviour and Genetics of Social Insects Laboratory, School of Biological Sciences A12, University of Sydney, Sydney, NSW \\ 2006, Australia \\ ${ }^{3}$ University of Lausanne, Biophore, 1015 Lausanne, Switzerland
}

\begin{abstract}
Recent evidence for genetic effects on royal and worker caste differentiation from diverse social insect taxa has put an end to the view that these phenotypes stem solely from a developmental switch controlled by environmental factors. Instead, the relative influences of genotypic and environmental effects on caste vary among species, ranging from largely environmentally controlled phenotypes to almost purely genetic systems. Disentangling the selective forces that generate variation for caste predisposition will require characterizing the genetic mechanisms underlying this variation, and identifying particular life-history strategies and kin structures associated with strong genetic effects on caste.
\end{abstract}

\section{Nature versus nurture}

In human societies, royalty is typically an inherited trait. In social insects, the opposite was once believed to be true: royals are made rather than born. For several decades, it was assumed that social insect broods are fully totipotent, and that environmental factors alone determine whether an individual becomes a reproductive royal, or a functionally sterile worker [1,2]. However, several recent studies have revealed that genetic factors can have an important role in queen and worker caste determination in some species [3-5]. But are these the exceptions or the rule?

In this review we argue that there is little or no evidence that the majority of social insect species are characterized by 'strict' environmental caste determination (ECD). Rather, it appears that caste determination systems vary along a continuum from ECD to genetic caste determination (GCD), where environmental factors no longer affect an individual's caste fate. We describe the proximate basis for genotype-caste associations in the species where genetic effects on castes are known to occur, and evaluate mechanisms generating and maintaining variation in caste predisposition. Although we focus solely on the bifurcation between royals and workers, most of the presented arguments should also apply to differentiation among worker castes, such as that found between specialized soldiers and nurses.

\footnotetext{
Corresponding author: Schwander, T. (tanja.schwander@gmail.com)

${ }^{4}$ Current address: Wissenschaftskolleg zu Berlin, Institute for Advanced Study,
} 14193 Berlin, Germany..
Little empirical support for strict ECD

Studies investigating the mechanisms of caste determination have identified the key environmental factors associated with the production of new reproductives $[2,6-8]$. These studies showed that food quality and/or quantity, temperature, queen pheromones, queen age and/or overwintering status, and colony size can influence whether or not reproductives are produced. Such findings are usually interpreted as evidence for ECD, consistent with kin selection and optimal resource allocation arguments (Box 1). However, whereas these findings show that environmental effects are important in caste determination, they do not provide evidence for an environmental caste system that is insensitive to genetic variation in caste predisposition among individuals. Most studies might have overlooked a genetic component, whereby, depending on environmental factors, a different set of genotypes are reared as reproductives or workers.

Demonstrating 'strict' ECD requires one to provide evidence that all genotypes in a colony have the same propensity to develop into a specific caste. Such evidence could be obtained by exposing larvae of different families to the same environmental conditions to test for caste-ratio variation among families, or, if diet is a good predictor for caste development, by artificially feeding larvae with different diets and monitoring their development. Such cross-fostering and feeding experiments have been conducted in the western honey bee (Apis mellifera), a species generally recognized as having strict ECD. Independent experiments have revealed that a large amount of food, or a protein rich diet, are a necessary and sufficient condition for the development of new queens [9-12]. Queen development can also be induced by down-regulation of a DNA

\footnotetext{
Glossary

Environmental caste determination (ECD): a system of queen and worker differentiation that is determined by environmental stimuli and largely insensitive to genetic factors (phenotypic plasticity).

Genetic caste determination (GCD): a system of queen and worker differentiation where an individual's genotype predicts its caste. Environmental stimuli do not affect the caste fate of a given genotype although they might determine which set of genotypes are raised.

Intermorphic queens: reproductive females morphologically intermediate between a typical queen and a typical worker. Queen traits include, for example, the presence of a spermatheca and large ovaries, worker traits include the lack of wings and associated thoracic structures and the absence (or reduction) of ocelli.
} 


\section{Box 1. Two reasons why genetic caste determination is} unlikely to evolve

Two independent theoretical arguments predict that environmental caste determination systems are more likely to occur than genetic systems.

Kin selection arguments for environmental caste determination

For kin selection to work as a theory for the evolution of altruism, alleles that generate altruistic behaviour must be carried by both helper phenotypes (workers) and reproducer phenotypes (queens) [77]. But this poses a problem, for alleles that reduce fertility in workers must either be expressed conditionally or have low penetrance $[78,79]$. If an allele for sterility were obligately expressed, it could not spread because its carriers would never have offspring $[80,81]$. Therefore, genetically hardwired caste systems can only be maintained under a restricted set of conditions, and genetic factors predisposing individuals for reproducer or worker development are predicted to be rare.

Optimal resource allocation arguments for environmental caste determination

Optimal resource allocation arguments also predict that reproducer and worker phenotypes should stem from differences in gene expression patterns rather than from underlying genetic differences. The life-cycle of an insect colony typically starts with a considerable investment into colony growth (worker production), which mirrors the somatic growth of a solitary organism [82]. The production of reproductives only starts after the colony has reached maturity $[83,84]$. With genetically-influenced caste determination, individuals are constrained (to a variable degree) in their development which might result in a non-optimal resource allocation into colony growth versus reproduction. Thus, other things being equal, colonies characterized by an environmental caste system should be selectively favored over colonies characterized by a genetic system.

methyltransferase (Dnmt3) in larvae [13], suggesting that diet affects caste development by mediating DNA methylation [14].

Whereas these honey bee experiments provide persuasive evidence for ECD, they do not exclude relatively minor genetic effects on caste. Indeed, indirect evidence indicates some genetic influence on the probability of individual larvae developing into queens or workers. Honey bee queens mate with many males and several studies have reported that subfamilies, i.e. the offspring of an individual male, differ in their relative contribution to the workers and replacement queens. In some studies, the subfamily frequency differences between queens and workers were small or insignificant $[15,16]$, whereas other studies reported significant differences with the proportion of overrepresented paternity among queens ranging from $4 \%$ $[17,18]$ to $20 \%[19,20]$. It appears that, depending on the nurse bees raising the brood, females from different subfamilies are preferentially raised as queens [21]. This suggests a complex interaction between brood and nurse bees instead of the presence of 'royalty alleles.'

Other than the western honey bee (A. mellifera), there is no direct evidence for ECD in social insects. In four species, however, indirect evidence suggests negligible genetic effects on caste determination. In the eastern honey bee, A. cerana [22], the ant Formica exsecta [23] and the wasp Vespula maculifrons [24], parentage analyses revealed no evidence for subfamily frequency differences between queens and workers. In the fungus-growing ant, Mycocepurus smithii, both new queens and workers can be produced parthenogenetically $[25,26]$, which, depending on the type of parthenogenesis, can directly indicate ECD
Box 2. Parthenogenetic production of queens and workers versus environmental caste determination

There are two categories of parthenogenesis that vary in whether egg production involves meiotic divisions or not. Under apomictic parthenogenesis, there are no meiotic divisions and each offspring is a perfect clone of its mother (with the exception of very rare conversion events) [85-87]. Apomictic production of both queens and workers by a single queen would therefore directly indicate environmental caste determination (ECD).

In contrast, automictic parthenogenesis produces genetically variable offspring and therefore does not indicate ECD. Egg production under automixis occurs via meiosis, whereby diploidy in the oocytes is usually restored either by fusion of two of the four meiotic products or by an additional step of chromosome duplication [85-87]. As a consequence, offspring can be homozygous at a locus at which the mother was heterozygous. Automictic production of queens and workers would be compatible even with a 'strict' genetic caste determination (GCD) model if only individuals heterozygous at one or several loci develop into queens.

(Box 2). ECD in M. smithii remains to be confirmed by determining the type of parthenogenesis [26,27].

\section{A continuum between ECD and GCD}

A genetic component to caste determination has been documented in 16 species (Table 1, Figure 1). Five of these (the ants Pogonomyrmex rugosus, $P$. badius, Acromyrmex echinatior, Formica truncorum and Cardiocondyla kagutsuchi) lie on the ECD end of the ECD-GCD continuum with the majority of genotypes being phenotypically plastic but biased towards worker or queen development. In another

Table 1. Examples along the environmental-genetic caste determination continuum. Data types include genetic analyses (G), experimental data ( $E$, breeding experiments and/or in vitro feeding), and indirect evidence (I). Note that a previous classification of genetic effects on caste [3] suggested a distinction between "strong genetic caste determination" (comprising genetically hardwired cases) and "weak genetic caste determination" (comprising all other genetic effects on caste).

\begin{tabular}{|c|c|c|c|}
\hline \multicolumn{2}{|r|}{ Species } & Data type & References \\
\hline \multirow{8}{*}{ 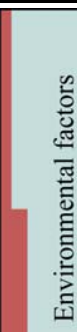 } & Vespula maculifrons & $\mathrm{G}$ & [24] \\
\hline & Formica exsecta & G & [23] \\
\hline & Mycocepurus smithii & I & {$[25,26]$} \\
\hline & Apis cerana & G & [22] \\
\hline & A. mellifera & $\mathrm{I}, \mathrm{E}, \mathrm{G}$ & {$[9-12,15-21]$} \\
\hline & F. truncorum & G & [23] \\
\hline & Cardiocondyla kagutsuchi & $\mathrm{E}$ & [31] \\
\hline & Pogonomyrmex badius & G & [30] \\
\hline \multirow{10}{*}{ 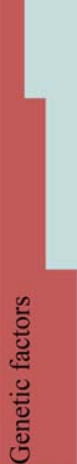 } & P. rugosus & $E, G$ & [28] \\
\hline & Acromyrmex echinatior & G & [29] \\
\hline & Harpagoxenus sublaevis & $\mathrm{E}$ & {$[34,36]$} \\
\hline & Leptothorax sp. A & $\mathrm{E}$ & [35] \\
\hline & Reticulitermes speratus & $\mathrm{E}$ & [37] \\
\hline & Melipona ssp & $\mathrm{E}$ & {$[39,40,45]$} \\
\hline & Pogonomyrmex lineages & $E, G$ & [50-52] \\
\hline & $\begin{array}{l}\text { Solenopsis xyloni } x \\
\text { geminata hybrids }\end{array}$ & G & {$[57,58]$} \\
\hline & Vollenhovia emeryi & G & {$[60,61]$} \\
\hline & Wasmannia auropunctata & $\mathrm{I}, \mathrm{G}$ & [59] \\
\hline
\end{tabular}




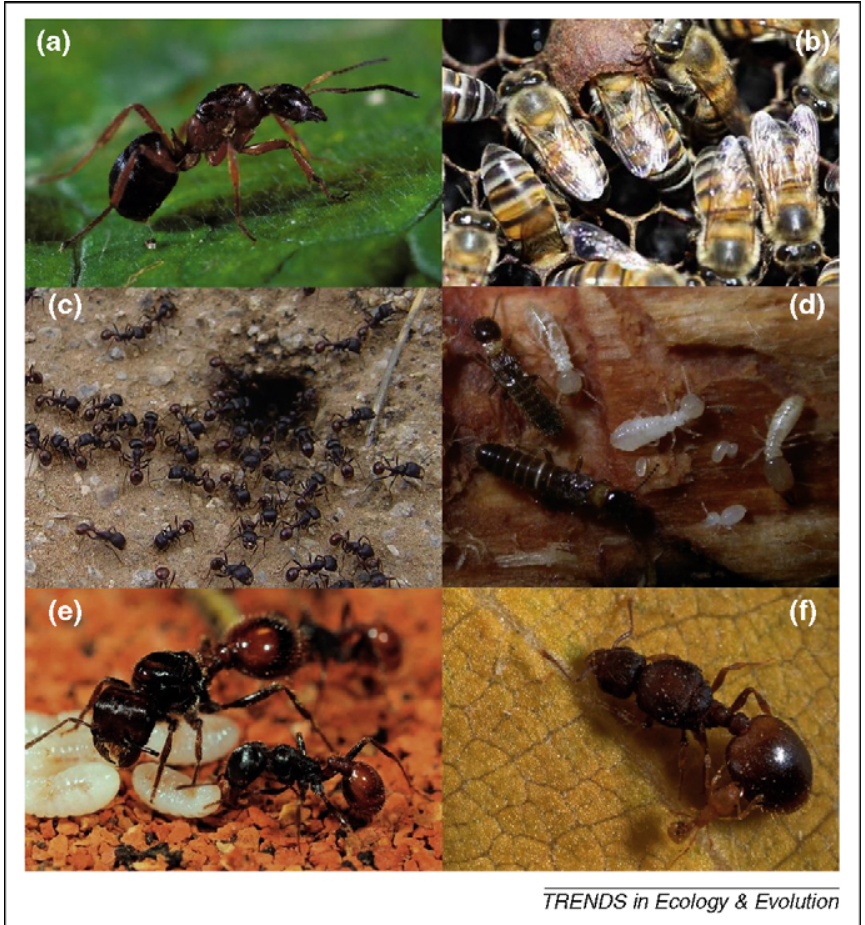

Figure 1. Species illustrating the range from largely environmental to largely genetic caste determination. (a) $F$. exsecta queen (image courtesy of Christian König); (b) A. mellifera workers tending an 'emergency queen' cell; (c) P. rugosus workers, (d) R. speratus incipient colony with a royal couple, workers and a soldier (image courtesy of Hitoshi Miyata); (e) worker, queen and larvae of Pogonomyrmex genetic caste determination lineages (image courtesy of Christian König); (f) W. auropunctata queen and worker (image courtesy of Christian König).

11 species (the ants Harpagoxenus sublaevis and Leptothorax sp. A of the L. muscorum complex, the termites Reticulitermes speratus, and at least eight species of the stingless bee genus Melipona), there seems to be a relatively equal contribution of genotype and environment to caste determination. Finally, four cases, all in ants, (Pogonomyrmex interdependent lineages, Solenopsis xyloni in certain hybrid zones, and some Wasmannia auropunctata and Vollenhovia emeryi populations) lie on the GCD end of the ECD-GCD continuum with environmental factors having little or no influence on caste determination.

\section{Species with minor genetic effects on caste}

In $P$. rugosus, caste is influenced by genetic compatibility between queens and their mates [28]. Different crosses between males and females from field colonies produced very different proportions of queens and workers. This variation was due to interactions between the paternal and maternal genomes rather than merely some lineages being predisposed for queen or worker development. In colonies with multiply-mated queens, these compatibility effects on caste development resulted in a shift in subfamily frequencies over the development from eggs to workers versus eggs to queens [28].

A similar pattern of subfamily frequency differences between workers and queens was also found in the ants A. echinatior, P. badius, and F. truncorum. In A. echinatior, approximately $20 \%$ of the subfamilies were overrepresented among queens [29], whereas this bias was only $4 \%$ in $P$. badius [30] and $12.5 \%$ in $F$. truncorum [23].
Because neither controlled breeding experiments nor estimates of subfamily frequencies in the eggs were conducted in these species, the genetic architecture underlying the variation in caste predisposition remains unexplained. In C. kagutsuchi, breeding experiments revealed significant variation in caste ratios among colonies whereby it is unknown whether the variation stemmed from (heritable) maternal effects on caste development or from direct genetic effects [31]. Finally, a genetic influence on caste has also been suggested in the ant Temnothorax curvispinosus on the basis of egg-fostering experiments [32]. However, because no crosses were conducted in this species, it is not possible to distinguish whether between-colony variation in caste production stemmed from genetic variation or from maternal effects influencing caste development, for example, via egg biochemical composition [33].

\section{Species with a relatively equal contribution of genetic and environmental effects on caste}

The ants Leptothorax sp. A and H. sublaevis are characterized by the presence of two types of reproductive queens, "normal" queens, and intermorphic queens with workerlike traits [34-36]. Crosses between individuals produced by normal and intermorphic queens revealed a genetic effect on queen morphology and caste determination. In $H$. sublaevis, normal queens mated to a son of a queen of the same type produced a three-fold greater queen:worker ratio than intermorphic queens mated to a son of an intermorphic queen. In Leptothorax sp. A, the difference was two-fold [35]. On the basis of these data it was proposed that queen morphology and caste determination are influenced by a locus with a recessive $(e)$ and a dominant allele $(E)$. The dominant allele would impair the development of wings, ocelli and thoracic sclerites in female sexual larvae and increase the probability of worker development relative to recessive homozygote females [34-36]. The difference in the penetrance of the dominant allele between H. sublaevis and Leptothorax sp. A suggests that other genetic and/or environmental factors might also affect caste development.

In eastern Japanese populations of the termite Reticulitermes speratus, caste depends on a sex-linked locus with two alleles with opposite effects in males and females [37]. Unlike the haplodiploid hymenoptera, termites are characterized by diploid sex determination (males have a Ychromosome) and have male and female wingless and functionally sterile workers. In Reticulitermes, new kings and queens develop from nymphs, a larval stage characterized by the presence of wing buds, but if the reproductive royal couple is removed from the colony, both workers and nymphs can become reproductives, termed ergatoids and nymphoids respectively. By conducting each of the four possible crosses between nymphoid and ergatoid individuals, Hayashi et al. [37] showed that differences in survival and caste ratio between offspring resulting from the four crosses was consistent with a biallelic X-linked caste-determining locus (Figure 2). The genotype matches phenotype in the absence of reproductives, genotypic nymphs develop into workers in the presence of reproductives, revealing that environmental factors still influence an individual's 


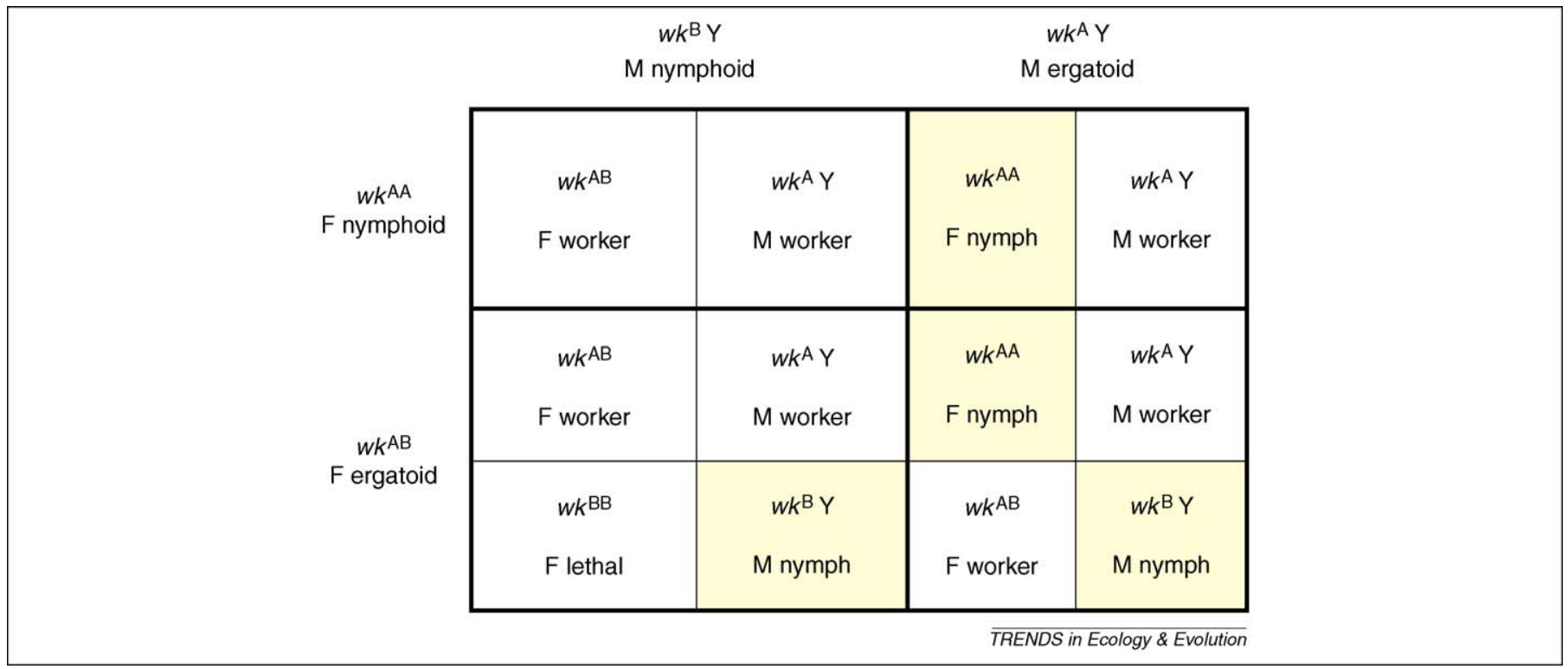

Figure 2. X-linked, one-locus-two-allele model for caste determination in $R$. speratus. Each cell displays the offspring genotype at the locus wk and the corresponding

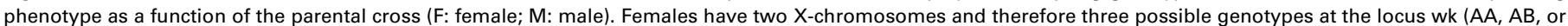

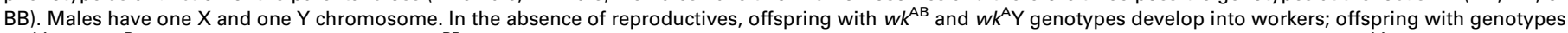
$w k^{\mathrm{AA}}$ and $w k^{\mathrm{B} Y}$ into nymphs. The genotype $w k^{\mathrm{BB}}$ is lethal. Female nymphoids and ergatoids also produce female nymphs parthenogenetically ( $w k^{\mathrm{AA}}$; not shown).

caste fate. Note that a different caste system has been described in western populations of the same species [38].

In meliponine stingless bees, genetic influences on caste have been proposed because field colonies produce a surprisingly high proportion of queens (approximately $12.5 \%$ or $25 \%$ depending on the species [39,40]). Because Melipona queens found new colonies accompanied by nestmate workers, there is no benefit in raising many queens [41] and workers execute the excess $[42,43]$. A biallelic, two or three-loci genetic model (dependent on the species) was proposed where only double, respectively triple heterozygotes can develop into queens, provided that they receive enough food $[39,40,44,45]$. Thus, independently of the genotype of the queen and her mate, random segregation produces $25 \%$ double heterozygotes in the two-locus system, or $12.5 \%$ triple heterozygotes in the three-locus system. This model is controversial [46], but independently of the underlying architecture, a genetic influence on caste was confirmed by studies showing that certain genetic markers were associated with the queen phenotype [45].

\section{Species with strong genetic effects on caste}

Many southern US populations of Pogonomyrmex contain differentiated genetic lineages, most or all of which derive from historical hybridization between the harvester ants $P$. rugosus and $P$. barbatus $[47,48]$. These lineages always occur in pairs [49] and queens in each lineage-pair mate multiple times with males of their own as well as with males of the alternate lineage. Interlineage offspring develop into workers, whereas intralineage offspring develop into queens [47,50-52]. Crossing experiments revealed that intralineage individuals are developmentally constrained to become queens [53]. Interlineage individuals have partly retained plasticity and can develop into queens under some conditions $[54,55]$, but the association of genotype and caste is very strong in natural populations, with only $0-7 \%$ of adult females (depending on the lineage and population [55]) presenting a mismatch between the genotype and expected phenotype. Based on these data, a genetic model was proposed, [47] in which two biallelic loci need to interact to trigger worker development (Box 3). Intralineage matings would result in allelic combinations that are incompatible with worker development, whereas compatible allelic combinations would be restored in interlineage matings and allow for worker and queen development.

A similar case of GCD associated with interspecific hybridization has been found in the genus Solenopsis [56,57]. In S. xyloni, colonies contain several queens, each mated with a single male. In areas of sympatry with

\section{Box 3. Genetic models explaining genetic caste determination (GCD) in Pogonomyrmex lineages}

A nuclear epistasis model was suggested to explain the loss of phenotypic plasticity in intralineage individuals of Pogonomyrmex lineages [47]. In this model two biallelic loci (alleles $a_{1}$ and $a_{2}$ at locus $A$, and alleles $b_{1}$ and $b_{2}$ at locus $B$ ) need to interact to trigger worker development. Only interactions between the alleles $a_{1}$ and $b_{1}$ or between $a_{2}$ and $b_{2}$ can generate worker development. Intralineage matings would result in allelic combinations that are incompatible with worker development (genotypes $a_{1} a_{1} / b_{2} b_{2}$ or $a_{2} a_{2}\left(b_{1} b_{1}\right)$, whereas compatible allelic combinations with correct interlocus communication would be restored in interlineage matings and allow for worker and queen development (genotype $a_{1} a_{2}$ l $b_{1} b_{2}$ ). This model could account for both the loss of phenotypic plasticity in intralineage individuals and the (partial) maintenance thereof in interlineage individuals. An alternative genetic model, based on cytonuclear epistasis, whereby only individuals with compatible cytonuclear combinations (i.e. intralineage individuals) can develop into queens [88] would require additional elements for explaining the patterns of phenotypic plasticity. In addition, given the evidence for (nuclear) compatibility effects on caste in $P$. rugosus [28], a parsimonious assumption is that GCD in the lineages is based on the same or a similar genetic system; this system might involve two loci as suggested in the original nuclear epistasis model or any larger number of loci. 
S. geminata, S. xyloni colonies contain queens either mated with a conspecific male or a $S$. geminata male. The type of mating has a strong influence on the fate of female offspring. Queens mated with a conspecific male produce only new queens, whereas queens mated to a $S$. geminata male only produce workers. New queens and workers in colonies headed by $S$. geminata queens at the same locations have typical $S$. geminata genotypes suggesting that the hybridization-linked caste system is restricted to $S$. xyloni [56].

A third GCD system has been identified in two other ants (W. auropunctata and V. emeryi) that use sexual reproduction to produce workers, and parthenogenesis to produce new queens [58-60]. Males reproduce clonally by a process involving the elimination of the female genome in fertilized eggs $[58,59]$ and/or some anucleate oocytes being fertilized and developing into haploid males [61]. Three lines of evidence indicate that caste determination is genetically hardwired in W. auropunctata. First, the phenotype-genotype match was perfect, with all workers being sexually produced and all queens being clonally produced [58]. Second, queens and workers are reared simultaneously so that the genotype-caste association cannot be explained by a seasonal production of parthenogenetic and sexual eggs. Finally, because workers are completely sterile, there is no opportunity for recombination between the male and queen genomes which have become highly differentiated [58]. Although less information is available in $V$. emeryi, the genotype-phenotype association seems weaker because up to $5 \%$ of the workers are produced parthenogenetically rather than sexually [60].

Consistent with the prediction that simple systems with worker-specific alleles cannot be stable across generations (Box 1), it appears that the four GCD examples are characterized by unusual reproductive systems that result in the re-introduction of worker-specific alleles via hybridization between differentiated genomes. It is important to note that such unusual systems are not necessarily associated with GCD. In contrast to W. auropunctata and V. emeryi, there is no evidence for GCD in another ant species, Cataglyphis cursor, where workers are also produced sexually and new queens parthenogenetically [62]. In this species there is a seasonal pattern with queens laying parthenogenetic eggs in spring when new queens are raised, and sexual eggs the rest of the year when workers are raised $[62,63]$. This, together with the facts that queens can be produced from fertilized eggs in the laboratory and workers also being able to produce queens by parthenogenesis, suggests that there is at least no strong genetic effect on caste $[62,64]$.

\section{Evolution and maintenance of genetic effects on caste} The examples in the previous sections show how the penetrance of genetic effects on castes vary among species and raise the question of the proximate and ultimate origins of this variation. Genetic effects on caste development are traditionally interpreted as evidence for 'cheating', whereby genotypes overrepresented among queens exploit the altruistic behaviour of other genotypes $[17,19,20,29]$. A female larva can, potentially, enhance her fitness by developing into a queen rather than a worker because she is usually more related to her own male and female offspring than to a sister's offspring $[41,65,66]$. Because the incentive for cheating should depend, among other factors, on nestmate relatedness, the frequency of caste-cheating should increase in concert with colony kin structure complexity $[41,65,66]$. Contrary to this expectation, most reports of genetic variation for caste are in species with a single queen per colony. This simplest possible kin structure with one singly-mated queen is characteristic in the meliponine stingless bees, a group traditionally considered as an example of caste cheating [67,68]. Queens are also singly-mated in $H$. sublaevis and Leptothorax sp. A., whereas they are multiply-mated in Pogonomyrmex, A. mellifera, A. echinatior and F. truncorum. There are only two known multi-queen species with genetic effects on caste, S. xyloni and W. auropunctata, both of which are unusual in that GCD depends on hybridization. However, the specialization in the production of specific castes by queens in other multi-queen species [69,70] could be indicative of more 'conventional' cases. Therefore, at present there is no support for genetic effects on caste determination being more prevalent in more complex societies. However, it is important to note that genetic effects are more likely to be detected in colonies with a single, multiply-mated queen than in single- and multi-queen societies with once-mated queens.

A potential problem with selfish elements generating variation for caste predisposition is that such elements should quickly spread to fixation [71]. Therefore, polymorphism should be maintained only if alleles favouring queen development are associated with negative effects such as reduced colony productivity $[18,41,68]$ or deleterious effects when the allele is in the homozygote form [37,72]. Costs associated with queen-biasing alleles could also stem from pleiotropic effects on traits unrelated to caste development [19]. For example, genetic variation for caste predisposition in H. sublaevis and Leptothorax "sp. A" is directly associated with genetic variation for queen morphology and could therefore be maintained by pleiotropy if there is spatial and/or temporal variation in the relative fitness of queens with different phenotypes, or optimal queen:worker ratios produced [73,74].

Alternatively, genetic effects on caste development could also be maintained if there are no strictly queen-predisposing alleles. The crossing experiments in $P$. rugosus have shown that genetic variation for caste development in this species stems from epistasis rather than additive genetic effects [28]. As a result, selection might be relatively inefficient at removing genetic variation decreasing the plasticity range of an individual. It is well known from classical genetic models that the architecture of a trait influences the maintenance of genetic variation [75], with relatively more variance maintained if the trait depends on epistasis, heterozygote superiority, genotype-by-environment interactions [75], or indirect genetic effects [32,76]. Interestingly, in addition to $P$. rugosus, such effects might also underlie the variation in caste predisposition observed in A. mellifera, the termites R. speratus, Melipona ssp. and the four groups with genetically hardwired caste determination (Table 1). In A. mellifera, the propensity of particular subfamilies to develop as queens is context-dependent, indicating that 
either genotype-by-environment interactions or indirect genetic effects are involved. In $R$. speratus, the maintenance of genetic variance for caste propensity might depend on the interactions between sex and caste-determining alleles (caste alleles have opposite effects in each sex). In the Pogonomyrmex lineages, the $S$. xyloni hybrid populations, W. auropunctata, and V. emeryi, caste is also determined by epistasis. In each system, the same set of alleles trigger queen development if interacting with alleles of their own species or lineage, whereas they trigger worker development if interacting with alleles of a different species. Finally, queen development in Melipona ssp. presumably requires heterozygosity (i.e. a case of "heterozygote superiority").

\section{Conclusion}

A critical review of the literature reveals that, surprisingly, there is no conclusive evidence for 'strict' ECD in social insects. Instead, it appears that there is considerable variation across species in the relative influences of genetic and environmental effects on caste determination. An interesting focus for future studies will therefore be to identify the factors responsible for this variation, for example the life-history traits and colony social structures frequently associated with 'strict' ECD or with strong genetic effects on caste. This would require a systematic quantification of the relative influence of genetic and environmental factors on caste across species.

Understanding how within-population genetic variation for the propensity to develop into queens or workers has evolved and can be maintained will ultimately involve identifying the genes and regulatory elements underlying the variation. Many genes are known to be differentially expressed between queens and workers both at the larval and adult stages [5] but none of them are known to harbor variants affecting caste development. Thus, virtually nothing is known about the proximate mechanisms underlying genetic effects on caste development. Genetic variation for caste could stem from variation in the sensitivity to an environmental stimulus (i.e. threshold variation) [3]. Accordingly, lineages that have lost phenotypic plasticity might have genetically-determined thresholds which are out of the range of the naturally occurring conditions. Alternative mechanisms affecting caste development include genetic variation for developmental speed or body size, or a loss-of-function of elements specific to either caste developmental pathway. Identifying the proximate mechanisms underlying variation for caste-propensity would provide an important step towards understanding the evolution queen-worker dimorphism and phenotypic plasticity in general.

The accumulation of evidence for genetic effects on caste in diverse social insect taxa also raises the question of whether ancestral caste systems were primarily environmentally or genetically determined and how they evolved over time. As previously suggested for the meliponine stingless bees [43], caste development could first have been entirely environmentally controlled with a genetic component evolving later. Alternatively, a gradual evolution of the worker caste phenotype could involve an initially genetic polymorphism followed by environmental control of the expression of the polymorphism. Overall, the end of the simplified view of pure environment caste determination in social insects has opened new research questions at the intersection of evolutionary and developmental biology as to how caste plasticity is shaped by selective pressures stemming from ecological factors as well as cooperation and conflict. The demonstration of complex interactions between genes in the process of caste determination also requires more care when attempting to provide ultimate explanations for the evolution of a genetic component to caste determination.

\section{Acknowledgements}

We thank Katrina Lythgoe and three anonymous reviewers for constructive comments. This research was sponsored by different grants from the Swiss NSF to T. S and L.K., the Australian Research Council to M.B., B.P.O., and N.L., the University of Sydney to M.B., and the Human Frontiers Science Program to M.B. Support during manuscript preparation was further provided by the Wissenschaftskolleg zu Berlin (Institute for Advanced Study) to T.S.

\section{References}

1 Crozier, R.H. and Pamilo, P. (1996) Evolution of Social Insect Colonies: Sex Allocation and Kin Selection, Oxford University Press

2 Wheeler, D.E. (1986) Developmental and physiological determinants of caste in social hymenoptera - evolutionary implications. Am. Nat. 128, $13-34$

3 Anderson, K.E. et al. (2008) The causes and consequences of genetic caste determination in ants (Hymenoptera: Formicidae). Myrmecol. News 11, 119-132

4 Lo, N. et al. (2009) Should environmental caste determination be assumed for termites? Am. Nat. 173, 848-853

5 Smith, C.R. et al. (2008) Genetic and genomic analyses of the division of labour in insect societies. Nat. Rev. Genet. 9, 735-748

6 Brian, M.V. (1979) Caste differentiation and division of labor. In Social Insects (Hermann, H.R., ed.), pp. 121-222, Academic press

7 Fletcher, D.J.C. and Ross, K.G. (1985) Regulation of reproduction in eusocial Hymenoptera. Annu. Rev. Entomol. 30, 319-343

8 Watson, J.A.L. et al. (1985) Caste Differentiation in Social Insects, Pergamon Press

9 Asencot, M. and Lensky, Y. (1976) The effect of sugars and juvenile hormone on the differentiation of the female honeybee larva (Apis mellifera L.) to queens. Life Sci. 18, 693-700

10 Haydak, M.H. (1943) Larval food and development of castes in the honeybee. J. Econ. Entomol. 36, 778-792

11 Weaver, N. (1957) Effects of larval age on dimorphic differentiation of the female honey bee. Ann. Entomol. Soc. Am. 50, 283-294

12 Shuel, R.W. and Dixon, S.E. (1960) The early establishment of dimorphism in the female honeybee, Apis mellifera L. Insectes Soc. 7, 265-282

13 Kucharski, R. et al. (2008) Nutritional control of reproductive status in honeybees via DNA methylation. Science 319, 1827-1830

14 Moczek, A.P. and Snell-Rood, E.C. (2008) The basis of bee-ing different: the role of gene silencing in plasticity. Evol. Dev. 10,511-513

15 Estoup, A. et al. (1994) Precise assessment of the number of patrilines and of genetic relatedness in honey bee colonies. Proc. R. Soc. Lond. B Biol. Sci. 258, 1-7

16 Franck, P. et al. (2002) Sperm competition and last-male precedence in the honeybee. Anim. Behav. 64, 503-509

17 Châline, N. et al. (2003) Patriline differences in emergency queen rearing in the honey bee, Apis mellifera. Insectes Soc. 50, 234-236

18 Moritz, R.F.A. et al. (1996) Competition for royalty in bees. Nature 384, $31-131$

19 Moritz, R.F.A. et al. (2005) Rare royal families in honeybees, Apis mellifera. Naturwissenschaften 92, 488-491

20 Tilley, C.A. and Oldroyd, B.P. (1997) Unequal subfamily proportions among honey bee queen and worker brood. Anim. Behav. 54, 1483-1490

21 Osborne, K.E. and Oldroyd, B.P. (1999) Possible causes of reproductive dominance during emergency queen rearing by honeybees. Anim. Behav. 58, 267-272

22 Koyama, S. et al. (2009) Absence of reproductive conflict during queen rearing in Apis cerana. Insectes Soc. 56, 171-175 
23 Keller, L. et al. (1997) Male reproductive success: paternity contribution to queens and workers in Formica ants. Behav. Ecol. Sociobiol. 41, 11-15

24 Goodisman, M.A.D. et al. (2007) Lack of conflict during queen production in the social wasp Vespula maculifrons. Mol. Ecol. 16, 2589-2595

25 Rabeling, C. et al. (2009) Thelytokous parthenogenesis in the fungusgardening Ant Mycocepurus smithii (Hymenoptera: Formicidae). PLOS One 4, e6781 doi:10.1371/journal.pone.0006781

26 Himler, A.G. et al. (2009) No sex in fungus-farming ants or their crops. Proc. R. Soc. Lond. B Biol. Sci. 276, 2611-2616

27 Fournier, D. and Aron, S. (2009) Evolution: no-male's land for an Amazonian ant. Curr. Biol. 19, R738-R739

28 Schwander, T. and Keller, L. (2008) Genetic compatibility affects queen and worker caste determination. Science 322, 552-1552

29 Hughes, W.O.H. and Boomsma, J.J. (2008) Genetic royal cheats in leafcutting ant societies. Proc. Natl. Acad. Sci. U. S. A. 105, 5150-5153

30 Smith, C.R. et al. (2008) Caste determination in a polymorphic social insect: nutritional, social, and genetic factors. Am. Nat. 172, 497-507

31 Frohschammer, S. and Heinze, J. (2009) A heritable component in sex ratio and caste determination in a Cardiocondyla ant. Front. Zool. 6, 27

32 Linksvayer, T.A. (2006) Direct, maternal, and sibsocial genetic effects on individual and colony traits in an ant. Evolution 60, 2552-2561

33 Schwander, T. et al. (2008) Maternal effect on female caste determination in a social insect. Curr. Biol. 18, 265-269

34 Buschinger, A. and Winter, U. (1975) Der Polymorphismus der sklavenhaltenden Ameise Harpagoxenus sublaevis. Insectes Soc. 22, 333-362

35 Heinze, J. and Buschinger, A. (1989) Queen polymorphism in Leptothorax sp. A: its genetic and ecological background. Insectes Soc. 36, 139-155

36 Winter, U. and Buschinger, A. (1986) Genetically mediated queen polymorphism and caste determination in the slave-making ant, Harpagoxenus sublaevis (Hymenoptera: Formicidae). Entomol. Gen. $11,125-137$

37 Hayashi, Y. et al. (2007) Sex-linked genetic influence on caste determination in a termite. Science $318,985-987$

38 Matsuura, K. et al. (2009) Queen succession through asexual reproduction in termites. Science 323, 1687-11687

39 Kerr, W.E. (1950) Evolution of the mechanism of caste determination in the genus Melipona. Evolution 4, 7-13

40 Kerr, W.E. (1950) Genetic determination of castes in the genus Melipona. Genetics 35, 143-152

41 Bourke, A.F.G. and Ratnieks, F.L.W. (1999) Kin conflict over caste determination in social Hymenoptera. Behav. Ecol. Sociobiol. 46, 287297

42 Engels, W. and Imperatriz-Fonseca, V.L. (1990) Caste development, reproductive strategies and control of fertility in honey bees and stingless bees. In Social Insects: An Evolutionary Approach to Castes and Reproduction (Engels, W., ed.), pp. 167-230, Springer-Verlag

43 Wenseleers, T. et al. (2004) Queen execution and caste conflict in the stingless bee Melipona beecheii. Ethology 110, 725-736

44 Michener, C.D. (1974) The Social Behavior of Bees, Harvard University Press

45 Hartfelder, K. et al. (2006) Physiological and genetic mechanisms underlying caste development, reproduction and division of labor in stingless bees. Apidologie 37, 144-163

46 Velthuis, H. and Sommeijer, M. (1991) Roles of morphogenetic hormones in caste polymorphism in stingless bee. In Morphogenetic Hormones of Arthropods (Gupta, A., ed.), pp. 346-383, Rutgers University Press

47 Helms Cahan, S. and Keller, L. (2003) Complex hybrid origin of genetic caste determination in harvester ants. Nature 424,306-309

48 Anderson, K.E. et al. (2006) Distribution and evolution of genetic caste determination in Pogonomyrmex seed-harvester ants. Ecology 87, 2171-2184

49 Schwander, T. et al. (2007) Characterisation and distribution of Pogonomyrmex harvester ant lineages with genetic caste determination. Mol. Ecol. 16, 367-387

50 Helms Cahan, S. et al. (2002) Extreme genetic differences between queens and workers in hybridizing Pogonomyrmex harvester ants. Proc. R. Soc. Lond. B Biol. Sci. 269, 1871-1877

51 Julian, G.E. et al. (2002) Genetic determination of the queen caste in an ant hybrid zone. Proc. Natl. Acad. Sci. U. S. A. 99, 8157-8160
52 Volny, V.P. and Gordon, D.M. (2002) Genetic basis for queen-worker dimorphism in a social insect. Proc. Natl. Acad. Sci. U. S. A. 99, 61086111

53 Helms Cahan, S. et al. (2004) Loss of phenotypic plasticity generates genotype-caste association in harvester ants. Curr. Biol. 14, 22772282

54 Anderson, K.E. et al. (2009) Modeling the maintenance of a dependent lineage system: the influence of positive frequency dependent selection on sex ratio. Evolution 63, 2142-2152

55 Schwander, T. et al. (2007) Two alternate mechanisms contribute to the persistence of interdependent lineages in Pogonomyrmex harvester ants. Mol. Ecol. 16, 3533-3543

56 Helms Cahan, S. and Vinson, S.B. (2003) Reproductive division of labor between hybrid and nonhybrid offspring in a fire ant hybrid zone. Evolution 57, 1562-1570

57 Hung, A.C.F. and Vinson, S.B. (1977) Interspecific hybridization and caste specificity of protein in fire ant. Science 196, 1458-1460

58 Fournier, D. et al. (2005) Clonal reproduction by males and females in the little fire ant. Nature 435, 1230-1234

59 Kobayashi, K. et al. (2008) Clonal reproduction by males of the ant Vollenhovia emeryi (Wheeler). Entomol. Sci. 11, 167-172

60 Ohkawara, K. et al. (2006) Clonal reproduction and genetic caste differences in a queen-polymorphic ant, Vollenhovia emeryi. Biol. Lett. 2, 359-363

61 Foucaud, J. et al. (2007) Sex and clonality in the little fire ant. Mol. Biol. Evol. 24, 2465-2473

62 Pearcy, M. et al. (2004) Conditional use of sex and parthenogenesis for worker and queen production in ants. Science 306, 1780-1783

63 Pearcy, M. and Aron, S. (2006) Local resource competition and sex ratio in the ant Cataglyphis cursor. Behav. Ecol. 17, 569-574

64 Pearcy, M. et al. (2006) Thelytokous parthenogenesis and its consequences on inbreeding in an ant. Heredity 96, 377-382

65 Reuter, M. and Keller, L. (2001) Sex ratio conflict and worker production in eusocial Hymenoptera. Am. Nat. 158, 166-177

66 Strassmann, J.E. et al. (2002) Caste totipotency and conflict in a large-colony social insect. Proc. R. Soc. Lond. B Biol. Sci. 269, 263-270

67 Ratnieks, F.L.W. (2001) Heirs and spares: caste conflict and excess queen production in Melipona bees. Behav. Ecol. Sociobiol. $50,467-473$

68 Wenseleers, T. and Ratnieks, F.L.W. (2004) Tragedy of the commons in Melipona bees. Proc. R. Soc. Lond. B Biol. Sci. 271, S310-S312

69 Bourke, A.F.G. et al. (1997) Parentage, reproductive skew and queen turnover in a multiple-queen ant analyzed with microsatellites. Proc. R. Soc. Lond. B Biol. Sci. 264, 277-283

70 Kümmerli, R. and Keller, L. (2007) Reproductive specialization in multiple-queen colonies of the ant Formica exsecta. Behav. Ecol. 18, 375-383

71 Hurst, G.D.D. and Werren, J.H. (2001) The role of selfish genetic elements in eukaryotic evolution. Nat. Rev. Genet. 2, 597-606

72 Keller, L. and Ross, K.G. (1998) Selfish genes: a green beard in the red fire ant. Nature $394,573-575$

73 Heinze, J. (1993) Habitat structure, dispersal strategies and queen number in two boreal Leptothorax ants. Oecologia 96, 32-39

74 Murakami, T. et al. (2000) Mating frequency, genetic structure, and sex ratio in the intermorphic female producing ant species Myrmecina nipponica. Ecol. Entomol. 25, 341-347

75 Maynard Smith, J. (1989) Evolutionary Genetics, Oxford University Press

76 Linksvayer, T.A. and Wade, M.J. (2009) Genes with social effects are expected to harbor more sequence variation within and between species. Evolution 63, 1685-1696

77 Hamilton, W.D. (1964) The genetical evolution of social behaviour. J. Theor. Biol. 7, 1-52

78 Charlesworth, B. (1980) Models of kin selection. In Evolution of Social Behavior: Hypotheses and Empirical Tests (Markl, H., ed.), Verlag Chemie GMBH

79 Seger, J. (1981) Kinship and covariance. J. Theor. Biol. 91, 191-213

80 Bourke, A.F.G. and Franks, N.R. (1995) Social Evolution in Ants, Princeton University Press

81 Crozier, R.H. (1979) Genetics of sociality. In Social Insects (Hermann, H.R., ed.), pp. 223-286, Academic Press

82 Seeley, T.D. (1989) The honey bee colony as a superorganism. Am. Sci. $77,546-553$ 
83 Cassill, D. (2002) Yoyo-bang: a risk-aversion investment strategy by a perennial insect society. Oecologia 132, 150-158

84 Oster, G.F. and Wilson, E.O. (1978) Caste and Ecology in the Social Insects, Princeton University Press

85 White, M.J.D. (1964) Cytogenetic mechanisms in insect reproduction In Insect Reproduction (Highnam, K.C., ed.), pp. 1-12, Royal Entomological Society of London
86 White, M.J.D. (1973) Animal Cytology and Evolution, (3rd edn), Cambridge University Press

87 Suomalainen, E. et al. (1987) Cytology and Evolution in Parthenogenesis, CRC Press

88 Linksvayer, T.A. et al. (2006) Genetic caste determination in harvester ants: possible origin and maintenance by cyto-nuclear epistasis. Ecology 87, 2185-2193 